\title{
THE ROYAL SOCIETY
}

\author{
ANNIVERSARY ADDRESS* BY SIR CYRIL HINSHELWOOD, F.R.S.
}

\begin{abstract}
NO'THER year of intensive preparation reached $\mathrm{A}$ its climax on November 13 when H.M. the Queen visited the Magga Dan, which was to convey the Royal Society expedition to the Antarctic, and when the members of the expedition were presented to her. The ship sailed two days later bearing the good wishes of all, on this combination of physical and scientific adventure which will make an important contribution to the International Geophysical Year. A great debt is owing to all who took part in the arrangements and especially to Sir David Brunt and to Dr. D. C. Martin, who have borne so much of the burden and heat of the day.

When he has completed a year of office, the President cannot but be very conscious of all that he himself owes to the other officers and to the staff at Burlington House. As the activities of the Society increase this becomes more and more one of the major things which need to be emphasized in this address. I must speak specially of the retiring 'Treasurer, Sir Thomas Merton, who is handing on his great responsibilities after seventeen years of unique service in that office. Sir Thomas took control of the Society's finances at a moment when they were beset by difficulties of all kinds. By a whole series of wise reorganizations, by a brilliant policy of reinvestment and by unremitting vigilance, he not only weathered the storm but has left the financial position of the Society stronger than it has ever been. Sir Thomas not only carries with him our grateful appreciation for what he has done, but also the assurance of an honoured place in the history of the Royal Society.
\end{abstract}

\section{AWARD OF MEDALS, 1956}

Copley Medal : Prof. P. M. S. Blackett, F.R.S.

Prof. Blackett has made important contributions to three main fields of physical discovery : the interaction with matter of fast particles from radioactive sources, the nature of the particles in the cosmic rays, and the magnetism of the Earth. In each of these he has combined outstanding insight and skill with novel developments in instrumentation.

During 1921-31 he was chiefly occupied with the development and operation of automatic Wilson cloud chambers and their application to the precise measurement of the parameters involved in collisions between $\alpha$-particles and atomic nuclei. He showed that very infrequent inelastic collisions with nitrogen produced the then unknown isotope ${ }^{17} \mathrm{O}$ by the capture of the $\alpha$-particle and the ejection of $a$ proton.

In this period also he verified, with Champion, the Mott theory of the wave-mechanical diffraction scattering of slow $\alpha$-particles.

From 1931 onwards he applied and extended the cloud-chamber technique to the study of the collisions involved in the cosmic rays, establishing (with Occhialini) the existence of nearly equal numbers of positive and negative electrons. This confirmed Anderson's discovery of the positive electron a few

* Delivered at the Royal Society on November 30 . months before and extended it by giving strong evidence for actual pair production. The $0.5 \mathrm{MeV}$. scattered $\gamma$-rays wero recognized by him to arise from the annihilation of positive and negative electron pairs.

Blackett proceeded to study in more detail the nature and the energy spectrum of cosmic-ray particles. Much valuable work on cosmic-ray showers. was carried out under his direction, and he himself explained the negative temperature coefficient of the cosmic rays in terms of the decay of the $\mu$-meson.

These detailed studies lod to a discovery which. opened up a new field when Rochester and Butler in Blackett's Manchester laboratory in 1946 found the first neutral $V$-particles and in 1947 the first charged $V$-particles. The identification by the Manchester team of $V^{0}$ decay into a proton and a pion and of the: probable division of a $V^{1}$ particle into two pions, together with the best determination to date of the life-times of $V^{0}$ and $V^{1}$ neutral particles, are outstanding further discoveries. These were made possible by Blackett's energetic action in moving the equipment to the observatory of the Pic du Midi.

From 1947 onwards he interested himself in the possibility, originally discussed by Schuster, of a 'fundamental' connexion between the angular momentum of a large rotating body, such as tho Earth, and its magnetic field. Although experiments conducted and directed by him gave no support to this idea, the sensitive magnetometer designed by Blackett for this work has been used by him and by Runcorn at Cambridge with success in remarkable studies of palæomagnetism and the light it can throw on polar wandering and continental drift.

Throughout his career Blackett has shown great ability and drive in organizing team effort in difficult fields of research. The building up of the Jodrell Bank radioastronomical station by Lovell owes much to him. He was awarded a Royal Medal in 1940 and the Nobel Prize for Physics in 1948.

Rumford Medal : Dr. F. P. Bowden, C.B.E., F.R.S.

Dr. Bowden is recognized as a leading research worker on the properties of solid surfaces. His early work was on the mechanism of the electrodeposition of ions at metal surfaces. He then turned his attention to the nature of the contact between solid surfaces and the mechanism of friction. He showed that however carefully surfaces are prepared they are generally covered with asperities large compared with atomic dimensions. When such surfaces are placed together, they touch at the tips of these asperities, which are crushed down until they are large enough to support the applied load. The area of real contact is thus independent of the size of the bodies and is proportional to the applied load; it is usually only a minute fraction of the geometric size of the bodies. At the regions of real contact strong adhesion occurs. The resulting friction arises from the shearing of the 
welded junctions formed at these points and to a lesser extent from the ploughing of one metal through the other.

Bowden has shown that because the area of true contact is so small, the work done in overcoming friction can raise the temperature of the local contact points to extremely high values. Ingenious methods for measuring this temperature were developed, and it was shown that in many cases surface melting may be produced which plays a fundamental part in processes such as polishing and the surface flow of solids. With modern physical methods he has studied the effect of surface films and in particular of boundary lubricants on the interaction between solid surfaces. This work forms the background to the modern theory of friction and boundary lubrication. The practical implications of the work are widely appreciated, and it has led to the development of new lowfriction surfaces, improved bearing materials and to the development of special lubricants.

Another phase of Bowden's work is the study of fast reactions in solids and the initiation and growth of explosion in crystals. This has led to a clearer understanding of the cause of accidental explosions and improved methods of manufacturing and handling explosive substances.

\section{Royal Medal (A) : Dr. Dorothy M. C. Hodgkin, F.R.S.}

Dr. Dorothy Hodgkin has made many outstanding contributions to our knowledge of the structure of complex organic molecules by the method of X-ray crystal analysis. Her best-known work is perhaps that on the structure of penicillin, and more recently her complete elucidation of the structure of vitamin $B_{18}$. In this work she has shown that it is possible to apply the methods of X-ray analysis to elucidate structures of molecules which are too complex to yield to the ordinary methods of chemistry.

With Bernal she obtained the first X-ray pattern from a protein single crystal (pepsin) in 1934, and from insulin in 1935. Later, with Schmidt, she made the first X-ray study of a virus single crystal (tobacco necrosis virus). With Bernal and Fankuchen she has completed a most comprehensive study of the crystallography of more than eighty sterol derivatives, belonging mainly to the cholesterol and ergosterol series.

It is perhaps in the field of complete structure determinations that her most important work has been done. She was among the first to realize the importance of the heavy-atom phase-determining methods, and these she used to effect the first complete determination of the geometry of a sterol derivative in her analysis of cholesteryl iodide. This was followed later by a similar analysis of a calciferol derivative and of a lumisterol derivative.

The same powerful phase-determining methods of analysis, and in particular her gift of being able to interpret correctly the complex and partially resolved electron-density patterns obtained, have been mainly responsible for her success in finally elucidating the structure of penicillin and of vitamin $B_{12}$. This last work is the most beautiful and complex analysis which has yet been achieved in this field.

Royal Medal (B) : Dr. O. T. Jones, F.R.S.

Dr. Jones is widely recognized as the most versatile of living British geologists, being equally at home when dealing with stratigraphical, structural, palæontological or petrological problems.

It was he who first worked out in detail the suceession of graptolitic sediments in central Wales, thereby bringing order into a vast area which had formerly been quite wrongly interpreted. More recently, with Pugh, he has, by detailed large-scale mapping, in the Builth area, revealed an example of an ancient Ordovician shore-line, with cliffs and beach deposits, thereby proving that large-scale elevation, erosion and deposition of many hundreds of feet of sediments can fall into the time represented by a single fossil zone, which elsewhere is indicated by only a few feet of sediments.

His work has thrown an entirely new light on the origin of certain complex structures in the sediments of the Lower Palæozoic rocks of north Wales. 'This study of 'slump structures' enabled him not only to point to the origin of the structures themselves, but also led him to use the detailed patterns in the sediments to interpret the general arrangement of land and sea during the time of their formation. The results of this study have revolutionized the views concerning the growth of the Welsh Palæozoic geosyncline.

In recent years he has published the results of a life-long study of the plateau surfaces of the Welsh mountain areas and traced their origin far back into geological time, thereby giving a firm foundation to the theories advanced by others concerning the river systems of Wales and the West Country.

His best-known work centres on his native Wales, but much of it also deals with more general topics, and of recent years he has taken much interest in the geological interpretation of geophysical results, where his wide knowledge of structural geology has enabled him to assess the value of the interpretation made by the geophysicists.

Wherever his researches have taken him, he has broken new ground and led the way to new lines of research.

\section{Davy Medal : Prof. R. D. Haworth, F.R.S.}

Prof. Haworth, over a period of some thirty-five years, has made outstanding contributions to the chemistry of natural products, particularly the alkaloids.

His first important work was on the isoquinoline synthesis of alkaloids in the aporphine, berberine and related groups. Later he extended his synthetic work on the aporphine group of alkaloids and in particular synthesized morphothebaine methyl ether, which was a connecting link between the thebaine and morphine groups of alkaloids.

In association with G. R. Clemo, he successfully synthesized a number of degradation products of santonin, and then with various pupils, particularly at Sheffield, he studied many natural pigmented compounds of high molecular complexity, notably retene and the phenolic resins which constitute the lignan group of natural products. Purpurogallin yielded up the secrets of its structure to him and he was able to synthesize this interesting compound in 1949. His discovery that it contained a tropolone ring led him to engage in tropolone chemistry, in which field he has made significant contributions, particularly to the study of novel substitution reactions. He has conducted valuable researches in the complex steroidal group of alkaloids, especially on conessine, he has investigated the fundamentals 
of the reaction of formaldehyde with proteins, and he has carried out numerous synthetic studies on a variety of complex nitrogen-containing natural compounds.

Darwin Medal : Dr. J. S. Huxley, F.R.S.

Dr. Julian Huxley has left his mark in a number of varied fields of biological science. His concept of the cline proved of such value in the description and understanding of geographical variation, in both its genetical and ecological aspects, that it passed almost immediately into very wide use. He was one of the pioneer students of courtship behaviour in birds; indeed, in his classical paper on the great crested grebe he gave the first descriptive analysis of mutual display and introduced the notion of mutual selection. He has contributed to the evolutionary study of behaviour and to the theory of sexual selection. He has given us the idea of allæsthetic selection and has defined allometry or heterogonic growth as it is variously called. His investigations of heterogonic growth in a variety of animals brought to light the existence of allometric gradient fields, the evolutionary implications of which he pointed out. His early genetical investigations of Gammarus led him to appreciate the evolutionary significance of rate genes, and he has recently discussed the significance of polymorphism, or morphism as he prefers to call it.

Yet to many his greatest work will have been the part he has played in the development of the neoDarwinian theory of evolution, of which he was indeed one of the earliest exponents. $\mathrm{He}$ is one of a number of biologists who have contributed in their various ways to this development, by experiment, mathematical analysis and theoretical discussion. Huxley has a place all to himself in that his wide interests, encyclopædic knowledge, and ability to see the connexion between widely separate fields, have enabled him to bring together and bind into a single evolutionary thesis the findings of the most diverse branches of biology. He has been one of the leaders in the rise of modern evolutionary biology, and a never-failing stimulus to those who have come into contact with him in this field.

Hughes Medal : Viscount Cherwell, P.C., C.H., F.R.S.

Lord Cherwell's earliest papers are mainly connected with specific heats at low temperatures, but include many contributions on such varied items as radiation pressure applied to cosmic problems, the transmission of X-rays and the structure of atoms and nuclei, including an approximate quantitative theory of the Geiger-Nuttall relation. His work on the solid state led to the well-known melting-point formula. In this connexion he began to take an interest in the photoelectric effect, connecting the frequency of the selective effect in the alkali metals with the characteristic frequencies, the latter being calculated either from the melting-point formula or by 'Rest-Strahlen' determinations.

During the First World War he worked at the Royal Aircraft Establishment. There he learnt to fly, and his main interests were concerned with the instruments of flight and with the problems of flight itself. He produced many technical papers in a wide range of subjects, including those on the theory of compasses, on the collision of aircraft with balloonbarrage cables, and on the conditions which caused vertical spin in aircraft in flight and the methods of extraction of the machine from spin when involved either accidentally or deliberately in such a manœuvre.

After the War he devoted himself in Oxford to the reorganization of an obsolescent department into the important laboratory it is to-day. Perhaps his most important direct contribution to physics was his pioneer work with Prof. G. M. B. Dobson on meteors, which led by means of calculations of the height, frequency and the temperatures of the trails to a considerable increase in our knowledge of temperature distribution in the upper atmosphere, particularly the increase in temperature above the stratosphere. The latter was satisfactorily explained by the absorp. tion of radiation by a layer of ozone. Further work was done on photoelectricity, mainly in connexion with its application to the determination of tem. perature, both in stars and in terrestrial sources, work which included the design of the well-known Lindemann electrometer. He has always been interested in astrophysics and cosmic phenomena, and has written many notes on these subjects. In particular, he has suggested the origin of magnetic storms as due to the recombination of electrons and ions in the upper atmosphere which arise from ionized clouds of gas ejected from the Sun, the velocity of the particles in the cloud being ascribed to light pressure.

In the Second World War he acted as scientific adviser to Sir Winston Churchill and produced a large number of reports and appreciations, many of which are mentioned in Churchill's book "The Second World War'.

\section{SOME INTERACTIONS OF THE PHYSICAL AND THE BIOLOGICAL SCIENCES}

The citations which have just been read leave no anxiety about the importance of the contribution which Fellows of the Royal Society make to the improvement of natural knowledge. In hearing them we may perhaps feel that passing regret which we experience on a journey when some fascinating vista opens at a new turn of the route, and we are moved by the desire to explore it while realizing that we never shall. We are swept onward about our own business.

People often think nostalgically of the early days of this Society when all the Fellows could understand everything that went on. Range and diversity were, however, available at the price of superficiality and incoherence when even Newton seems to have felt that his view of Nature consisted after all of a series of very imperfectly related parts. 'To-day the whole has more structural unity, yet often seems so vast and labyrinthine that we get lost if we venture beyond our own small locality, which itself reveals subtleties and complexities multiplying almost without limit the more closely we look.

'The process of elaboration, though deplored in one quarter or another almost daily, is not quite irreversible. As in all the great movements of Nature or of humanity, there are opposing tendencies and com. pensating reactions. On one aspect of this matter I shall dwell a little now.

At one time the segregation of the physical and the biological sciences could scarcely have been more complete. It is reflected indeed in the dichotomy of the Royal Society itself. 'The lines of demarcation are gradually vanishing, and our duplex structure is becoming something of an anachronism. 
The fusion is occurring in many places : the interpretations of nerve action in terms of ionic flow, and of cortical events in terms of spatio-temporal patterns of neuronal activity; the analogies between the working of the brain and the operations of electronic calculators; all these and many more have for a long time compelled the simultaneous study of widely different fields of science.

It is difficult to think oneself back to the time when the preparation of urea from ammonium cyanate caused something of a sensation in the world. In his "Essays on Historical Chemistry" Thorpe wrote: "That particular day in 1828 when Wöhler first observed the transformation of ammonium cyanate into urea should be accounted a red letter day in the history of science".

'Things have moved since then; structures have been determined and syntheses achieved for every kind of vital product from the anthocyanins of flowers to the adenosine triphosphate which so subtly regulates the energy exchanges in the cell. A year or two back the pituitary hormone oxytocin was synthesized by du Vigneaud and his collaborators, and the synthesis of another peptide pituitary hormone has been announced this year. Steroids are the object of unremitting and successful work in several laboratories, and nucleotide coenzymes continue to yield to the investigators of Todd's school, the total synthesis of cozymase having recently been carried out.

The relation of molecular structure to properties is a major chapter of science and now forms a body of doctrine built up over a century. Through the stimulus, partly industrial, of the intensive work on polymers-those huge molecules now made almost to a predetermined specification of properties-this study to-day embraces some of the chief constituents of the living cell.

Natural compounds of very high molecular weight, formed at low temperature and under the directing influence of existing cell structures, have normally a much more regular configuration than the chains randomly formed in polymerizations initiated by free radicals at high temperatures. The gap between the natural and the artificial has been significantly narrowed by the recent discoveries of Ziegler and of Natta. By the use of new catalysts based upon aluminium alkyls and titanium or vanadium chlorides, beautifully oriented polymers of regularly repeating structures are formed. The initiation mechanisms may well be ionic, and the regularity is almost certainly due to the guiding influence of a heterogeneous catalyst.

The closer approach of this mechanism to that used in the cell is very suggestive. Substances closely resembling natural rubber and guttapercha (which stand in a cis-trans relation to one another) have indeed been made by such means. The properties of these regularly ordered polymers are profoundly different from those of the less ordered forms, and during this year Natta, Corradini and Dall'Asta, in a study of crystalline polypropylene oxide, comment on the notable analogies between their product and the fibroin of silk.

In this general connexion the recent work of Ballard and Bamford is highly suggestive. These authors find that in the polymerization of DL-phenyl. alanine- $\mathrm{N}$-carboxy $\alpha$-amino-acid anhydride initiated by polysarcosine dimethylamide, the polysarcosine chain is able to catalyse the reaction between the base and the anhydride in a marked degree. They justly point out the analogy between this phenomenon and an enzyme reaction.

Work continues in many laboratories on the fibrous and globular proteins and on nucleic acids (and models have recently been shown to the Royal Society of the beautiful structures which the X-ray crystallographers are beginning to propose for these vitally important substances).

The problem is enormously complicated, but its attraction depends, of course, largely upon the belief, widely held on good grounds, that these structures are fundamentally concerned in the processes of heredity. Nevertheless, the view that nucleoproteins are the basis of genes which could ever be selfreplicating in isolation and merely in virtue of their structure is probably a dangerous over-simplification.

In the chemistry of inanimate Nature the study of structure alone is quite insufficient and must be undertaken in conjunction with that of function; in other words, reaction mechanisms are as important as molecular structures.

That the properties of living things are an emergent result of contributions from finite, if large, numbers of structural units or genes, that the genes are rather stable though not immutable, that in proper circumstances they change their associations in accordance with the laws of probability, are among the major basic principles of science. Recent work has, however, widened the view of the ways in which hereditary characters are transmitted. Besides sexual unions there are transmission by infective agents, by transduction and by Pontecorvo's parasexual mechanisms. Moreover, the combinatory phenomena that are so important in the Mendelian system cannot play much part in micro-organisms which multiply by binary fission. Fruitful as the reference of cell properties to the structure of genes has been, the body of doctrine which rests on this assumption is in some important respects incomplete, as indeed every chapter of science must be incomplete by itself. The picture presented is essentially static. The phenomena of growth, adaptation and reproduction need a dynamic one.

No one structure is likely to be autosynthetic in isolation; even the viruses require as hosts more or less intact cells, the machinery of which they can exploit. The building blocks of the cell, wonderful though they may be as structures, are useless by themselves. Cell function depends upon the rhythm and harmony of their reciprocal actions: the mutual dependence of protein and nucleic acid; the spatial and temporal relations of a host of elementary processes which with their sequences and bifurcations make up the reaction pattern of the cell. A system of mutually dependent parts, each of which performs something like enzymatic functions in relation to another, will, as can easily be shown, in the steady state appear as a whole to be autosynthetic. No individual part need be credited with a new and mysterious virtue by which to duplicate itself. Thus the picture widens beyond the structural units to their quantitative proportions, to their reciprocal dependence and to their rates of growth. This fusion of physical chemistry and biology leads to conclusions about the nature of adaptive processes, the automatic attainment of maximum growth-rates, and mechanisms for the choice of the most favourable metabolic patterns (as in the Pasteur effect).

The reality of the dynamic picture is sometimes called in question because there may be alternative explanations of particular phenomena. For example, the important phenomenon whereby drug resistance 
develops is often referred exclusively to selection of random mutants, although it is easy to show on the basis of very general physico-chemical assumptions that the effect should demonstrably occur as an automatic response, the adapted cells having reorganized their reaction patterns. This conclusion in its turn in no way denies the possibility of spontaneous resistance due to structural mutations. Nor, on the other hand, does the occasional demonstration of mutations leading to resistance rule out automatic cytoplasmic adjustments.

One possible prescription for steering between the opposite hazards of narrowness and of superficiality is to try to set the particular objects of one's own interest into a general framework, working with a large map but filling in small areas with as much detail and accuracy as possible. Partly on this principle, but also, I confess, a little to vindicate my feeling that a president of this Society, whatever his other prooccupations, has the right and duty to remain a working man of science, I am proposing to devote a few paragraphs to some matters, relevant to the general theme, but closely connected with one of the fields of my own activity.

Resistance to the idea that some biochemical adaptations of cells are due to automatic internal reorganization has been largely founded on the relative stability of such changes, and upon the doctrine that heredity only changes by spontaneous gene mutation. Evidence, however, accumulates that adaptive processes are indeed reversible. Aerobacter aerogenes, once it has acquired the power of utilizing D-arabinose $\left(A^{+}\right.$character), holds it for a long time, but some strains of Escherichia coli revort rather quickly. Cross found that with Aerobacter loss of the $A^{+}$character occurred more rapidly in certain media which themselves imposed a new adaptive necessity on the cells. The effect might have been attributed to a re-selection in these media of a small residual contamination of $A^{-}$(or of reverse mutants); but this explanation was ruled out by comparative experiments with artificial mixtures of the $A^{+}$and $A^{-}$types. The real reversion of the population in conditions not favouring the selection of the $A^{-}$cells showed that arguments based upon the assumed permanence of the change are inadmissible.

The impression that drug resistance is a necessarily stable character is weakened still further by the study of micro-organisms other than bacteria. Wild found that with strains of Saccharomyces cerevisiae the degree of persistence of adaptation to various inhibitors is very variable.

Other evidence bearing on the nature of the adaptive changes responsible for drug resistance comes from the detailed study of time-number relations in colony formation on agar plates containing an inhibitory substance. If, say, $10^{8}$ cells are plated on a solid medium containing a drug at a suitable concentration, there may appear $10-100$ welldeveloped colonies which have been widely regarded as spontaneous mutants. But if the statistical distribution of the times at which they appear is compared with that for a correspondingly small number of cells previously adapted to resist the drug, then the comparison shows that the few survivors from the unadapted strain have formed colonies much more slowly than the members of the adapted strain. Individuals of this latter could therefore not have been present in the original even in the minute numbers supposed. Results of this kind have been found by Wild with yeast and by Dean with some bacterial strains. In some of these examples, moreover, the non-existence of minute numbers of the adapted forms in the original population is demonstrable even when the standard of resistance studied is quite $a_{0}$ low one. Thus alternative explanations based upon complex series of inultiple mutations would be forced to include highly unlikely assump-
tions.

One method by which pre-existent mutants arc often tested for may be illustrated in the example of the well-known Bacterium coli mutabile. 'This organism normally refuses to grow on a lactose-agar plate except after a long delay. If, however, a very large inoculum of cells of the order $10^{8}$ or $10^{8}$ is plated, some colonies develop much more rapidly, and their number has been used to give a measure of the mutation-rate to the so-called lactose-positive condition.

Dean undertook a study of the statistics of colony formation by this organism on lactose-agar plates, measuring the distribution of colony sizes at various times, and the distribution of the times required for the formation of colonies of various standard sizes. The results conformed rathor closely to Gaussian distributions, and the relatively few early-forming large colonies which might have been labelled lactosepositive mutants did not seem to be more frequent than the Gaussian law could permit in so enormous a population.

All these observations support the view that the cell makes adaptive changes by dynamical adjustments as well as by any mutations which it may suffer.

Normally, mutations, apart from those caused by radiation or special chernical agents, have been supposed to occur only when cells divide. This view itself seems to be changing.

Some years ago, Baskett made a number of observations individually and collectively indicating that during the long delay which attends the first growth of Bact. lactis aerogenes on D-arabinose thero is in fact a physiological adaptation of the cytoplasm, and not the selection of mutants. Generally similar results have been found by Dean for cells initially. reluctant to use lactose.

Somewhat analogous observations in a more spectacular form were reported by Akiba, and more fully by Szybalski. Bacterial strains exposed to streptomycin for a number of days in a buffer not supporting growth were found eventually, if they had survived at all, to have become resistant to the antibiotic. Szybalski, however, quotes what he calls "tentative evidence" that the changes occur in a nucleus. This evidence is derived from observations on the crossing or transduction phenomena which occur with certain strains of Escherichia coli and Salmonella.

The conclusion, however, seems to be far from certain, since the relations found in crossing drugresistant with sensitive organisms are usually very complex. In genetic analysis with micro-organisms the number of parameters which can be adjusted is considerable, and illusory effects of sharp segregation phenomena are sometimes produced by the process of dividing continuous variables such as rate or time of growth into arbitrary domains such as 'slow' and 'fast' or 'plus' and 'minus'. 'That a high percentago of non-dividing cells should suffer nuclear mutations making them resistant precisely to that drug to which they are being exposed seems much harder to explain than the alternative of a dynamical change 
by which the cell as a whole reacts to the presence of the drug in an almost predictable way. The same general comments might be made about the 'spontaneous mutations' in the absence of division, to histidine-independence of a bacterial strain recently studied by Ryan.

In spite of some alarm, physico-chemical mechanisms of cell adjustment need not be in any conflict at all with valid principles of genetics. But it is a misapplication of the latter when they are used to exclude all mechanisms except selection of random mutants or of favourable gene combinations. Random mutations to drug resistance may indeed be shown by the relatively rare examples where the Lederberg technique of replica plating has given positive results. Nature, however, presents us with a vast hierarchy of systems : sub-atomic units (in a vast and confusing array), atoms and molecules, micelles, chromosomes, nuclei, cells, colonies, tissues, individuals and communities of individuals. Nobody can suppose that all phenomena have their origin at any one particular level.

In the organisms studied by classical genetics, individuals develop from fertilized germ cells, and, not surprisingly, show characteristics largely inherent in those cells. In micro-organisms which multiply by binary fission, the new individual does not develop from a much smaller germ cell but is formed by the approximate halving of an existing one, and, no more surprisingly, shows the characteristics of this. The manifestation of the effects of genes has long been recognized to be profoundly affected by their environment, so that the subsequent growth of the divided daughter cells is largely governed by the total organization. This explains-and more specific physico-chemical illustrations can be given-why such characters as drug resistance due to enzymatic reorganization can persist through many divisions. But to call the phenomenon or its interpretation Lamarckian is a plain misuse of language.

The disentangling of the complicated and fasginating relationships met with in this field will demand close co-operation of the physical and biological sciences, which brings me back to the keynote of this address. To the highly ingenious models of structure must be added equally illuminating models of function. Whatever the answer may be to the controversial problems of to-day, that is what the future in one way or another will surely bring forth.

\section{OBITUARIES}

Prof. Winifred Cullis, C.B.E.

By the death on November 13 of Prof. Winifred Cullis the world has lost not only a fine scientist but also an outstanding personality.

Winifred Clara Cullis was born in Gloucester on June 2, 1875. King Edward VI's High School for Girls, Birmingham, and Newnham College, Cambridge, laid the foundation of her abiding interest in science and began many life-long friendships. In 1901 she was appointed demonstrator in physiology at the London (Royal Free Hospital) School of Medicine for Women; later she became lecturer, reader and head of the Department, and finally professor of physiology in the University of London. She retired during the Second World War.

From the beginning, research was Prof. Cullis's great interest, and her name will always be associated with two outstanding pieces of work, one on the mechanism of the secretion of urine and the other on the perfused isolated heart of rabbit. Her experimental technique was precise and careful, and it was a joy to see the delicacy and sureness with which she would snip sufficient of the auriculo-ventricular bundle in the beating heart in order to demonstrate the effects of partial heart block. In later years lectures at home and abroad made continued research work more difficult; but periodically she would give herself a 'holiday' and with one or more colleagues settle down for several weeks investigating some interesting problem. She gave unstintingly of her knowledge and wide experience to her departmental colleagues but always insisted that publications should be in their own names, and any appreciation of their work gave her great pleasure.

No one who knew her could be other than filled with admiration for the absolute integrity and shining honesty which characterized her scientific outlook and the public work which later claimed so much of her time. For self-seeking, pomposity or hidden motives she had no use, and nothing was more direct than her own approach to a problem.

This directness, together with her gaiety and wit, made her lectures and speeches unforgettable. She had a store of appropriate stories-often against herself-and it was seldom that a specch of hers was not punctuated by laughter.

She herself realized how valuable were her special gifts as a speaker, and she gladly spoke for any cause she had at heart, particularly where she felt she could assist in securing for professional women equal opportunity and status with men. Her great charm was to a large extent due to her intense interest in and understanding of her fellow men and women. 'This and her generous appreciation of the other person's point of view, even when she disagreed, was particularly valuable in international contacts. In her work for the British Federation of University Women and for the International Federation of University Women, in each of which organizations she held the presidency for a number of years, she combined her interest in the advancement of women and her belief in the great value of international understanding and good will

Of the many honours and marks of appreciation that came her way, few gave Prof. Cullis greater pleasure than the decision of the British-American Associates to name one of their lecture fellowships after her.

She felt strongly that physiology should be taught in the schools and gave a series of most successful talks in the B.B.C. Schools Programme. She wrote two excellent books on the subject for use in schools. "Your Body and the Way it Works", published in 1949 , is a very clever blending of her text with pictures by Ian T. Morison. Included is a section on growth, reproduction and heredity which is an aspect of human biology normally omitted from elementary books. 